\title{
REPORT
}

\section{High altitude training - developing an international centre for Sri Lanka: evaluating for the best outcome}

Chathuranga Ranasinghe ${ }^{1,2}$, Prasanna Gamage ${ }^{3}$, Olivier Girard ${ }^{4}$, Romain Perera ${ }^{1}$, Lakshitha Ranasinghe ${ }^{5}$, Ruwanika Seneviratne ${ }^{5}$, Lalith De Silva ${ }^{6}$

\begin{abstract}
This article is based on the detailed inception report on technical evaluation, which was presented on request to the Ministry of Sports, Sri Lanka in J une2017, proposing theestablishment of a Sports MedicineHuman Performance and Research Centre at the planned High Altitude Training Centre (HATC), Nuwara Eliya, Sri Lanka. The report was compiled by the Sports Medicine and Research Evaluation Team at the Faculty of Medicine, University of Colombo and the Project Consultancy Unit, University of Moratuwa in collaboration with international content experts. The objective of this reportwas to inform theSports Medicine requirements that should beconsidered during development of the high altitude training centre in Sri Lanka. Thisarticle discusses the scientific basis of altitude training, the glo bal context listing several international centres for altitude training and the Sri Lankan context with the assessment of the environmental suitability and recommendations based on available evidence.
\end{abstract}

\section{Introduction}

High altitudes are defined as geographical locations 3000-5500 m above sea level. Different research studies, various professional bodies and institutions worldwide have specific definitions for 'high altitude'. The consensus statement of FIFA Sports M edical Committee 2008, defines el evations between 0-500 $\mathrm{m}$ as ' $\mathrm{N}$ ear sea level', above $500 \mathrm{~m}$ - $2000 \mathrm{~m}$ as 'Low altitude', $2000 \mathrm{~m}$ - $3000 \mathrm{~m}$ as 'M oderate altitude' and above $5500 \mathrm{~m}$ as 'Extreme altitude' [1, 2].

Training at low-to-moderate altitudes (500-3000 $\mathrm{m})$ has long been used with endurance athletes to

${ }^{1}$ Department of Allied Health Sciences, Faculty of Medicine, University of Colombo, Sri Lanka.

${ }^{2}$ Queensland University of Technology, Brisbane, Australia.

${ }^{3}$ School of Health and Life Sciences, Federation University, Australia, Mt Helen VIC 3350, Australia.

${ }^{4}$ Murdoch Sport Science Laboratory, Murdoch University, Perth, Australia.

5 Planning Division, Ministry of Health, Sri Lanka.

${ }^{6}$ Project Consultancy Unit, Faculty of Architecture, University of Moratuwa, Sri Lanka.

Correspondence: CR, e-mail: chath_r@yahoo.com.au> enhance subsequent sea level endurance performanceor to acclimatise to competition at altitude. This mainly occurs through the elevations in blood parameters and/ or other means of improving oxygen transport and utilisation [3, 4]. This phenomenon of metabolic adaptation provided athletes an alternative mechanism to increase endurance, and thereby, their level of performance in sports. This interest in Altitude Training (AT) has grown since the 1968 Olympics in Mexico City $(2400 \mathrm{~m})$, when the impact of hypoxia on sport performance becameclear [5]. This has revolutionized the training of athletes for competitions sincemost of eliteathletes engaged in individual endurance sports arenow using AT [6] and athletes from different 'team sports' worldwide engagein AT morethan ever before.

\section{The science behind human body responses to altitudes}

Human physiological adjustments as a result of exposureto altitudeenvironments have been studied from the $17^{\text {th }}$ century by various scientists.

The science behind the response of the body to altitudes at rest is well understood. The environmental hypoxia (low oxygen levels in the inspired air) that is observed in altitudes results in a series of 
physiological adaptations in thebody that increases oxygen carriage by blood and utilisation by the muscles [7]. Thelong term physiological benefits or theadaptations to altitudes is mainly by the increase production of red blood cells in the body through stimulation of erythropoietin hormone, which increase due to low oxygen levels in blood (hypoxaemia). This in turn increases the oxygen carrying capacity of blood and endurance-like performance.

Research on body's response to altitude while exercising, has devel oped over the recent past. The hypoxic stress may not betheonly factor involved in theenhancement of performanceduring training since other central (e.g., ventilation, haemodynamics or neural adaptations) and/ or peripheral (e.g., musclebuffering capacity or economy) factors may also play an important role.

A negative aspect to the physiological effects of acclimatization has also been studied extensively. Research studies haveidentified decreasein theblood flow to skel etal muscles, larger risk of dehydration, depression of immunity from living in high altitudes, possible effects of decrease in the absolute training intensity, decreased plasma production and increased destruction of red blood cells (haemolysis) after returning to low altitudes [8]. This highlights that best practice once training at altitude would need to beinformed by research in order to maximizetraining responses and minimize potential side-effects of chronic hypoxic exposure.

\section{Types of altitude training}

Training that can be completed at altitudes has evolved considerably and can be categorized into threedistinct types [4, 9].

1) Live-high train-high (LHTH)

2) Live-high train-low (LHTL)

3) Live-low train-high (LLTH)

Thesetraining modalities can beachieved with natural altitude, simulated altitudeor a combination of both. The LHTH method involves both living and training at low-to-moderate altitudes to induce positive hematological adaptations. A potential limitation of this techniqueincludes decrease in the aerobic capacity of theperson with altitude (1\% drop for every $100 \mathrm{~m}$ altitude ascent above $1500 \mathrm{~m}$ ) [10]. This limits training intensities where athletes can't train at similar high intensities than they would normally do near sea level. The LHTL involves living at high altitude while training at lower elevations.
This can be achieved either through travelling between different altitude locations or through the use of artificial means of reducing oxygen delivery to the body, such as use of masks (hypoxicators and portabledevices) or living in a low oxygen environments (e.g. nitrogen house, hypoxic chamber). With the LLTH approach athletes breathe hypoxic air during their usual exercisetraining, whileliving near sea level. Today, the LHTL intervention is probably recognized as the "gold standard" for maximized normoxic exercise performancegains in athletes [11].

The duration of residence/ training at al titudes has also been considered a major factor dictating what is the preferred AT method to implement. Although there is no clear consensus today in the scientific community, in individual athletes, the success of altitude training may require living high enough ( $>1800 \mathrm{~m}$ ), for enough hours a day ( $>12-14$ hours/ day), for a sufficient period of time ( $>15$ days), in order to sustain an erythropoietic effect of hypoxia; $(\sim 250-300 \mathrm{~h})[4]$.

\section{High altitude illnesses}

There have been cases during events such as mountain races, athletes may experiencevery rapid ascent to high altitudes, which places them at high risk for developing altitudeillness [12]. At any point 1-5 days following ascent to altitudes $\geq 2500 \mathrm{~m}$, individuals areat risk of developing one of threeforms of acute altitude illness. Acute mountain sickness (AMS), a syndrome of nonspecific symptoms including headache, lassitude, dizziness and nausea; high-altitudecerebral oedema (HACE), a potentially fatal illness characterised by ataxia, decreased consciousness; and high-altitude pulmonary oedema (HAPE), a non-cardiogenic form of pulmonary oedema resulting from excessivehypoxic pulmonary vasoconstriction which also can be fatal [13]. Risk factors for developing high altitude illness include previous history of high altitude illness, a faster rate of ascent, higher elevation, poor hydration, increased intensity of physical activity, and individual variability [12] .

Slow ascent to altitude is the hallmark of prevention for all acute high altitude illnesses. Guidelines recommend that once above $2500 \mathrm{~m}$, altitude should be increased at a rate of $400 \mathrm{~m}$ to $500 \mathrm{~m}$ per day $[14,15]$. Duration of an effective acclimatization also depends on the athlete's residing altitudeand the altitudeto which the athleteplansto ascend. 
The athletes may be at lower risk for these illnesses at lower elevation less than $2000 \mathrm{~m}$, at the proposed centre in N uwara Eliya. Still appropriate measures should be in place as some individuals who are highly susceptible to acute altitude illness may becomesymptomatic at al titudes $<2500 \mathrm{~m}$ [13]. A cute mountain sickness (AMS) can be more common in thelower elevations. Theathletes of poor subjective sleep quality is should be cautious as insomnia can becomea risk factor for AMS.

\section{Recent advances in altitude training}

With the advancing research, new approaches likeintermittent hypoxic interval-training (IHIT) and living high-training low and high (LHTLH) (16) techniques have been developed. They can improve physical performance, and can be specifically tailormadefor team-sport use, in order to better resist fatigue in themoreintense periods during a gameor towards match-end [4].

Currently, high altitude training is not only reserved to endurance athletes as in the past. Different sports will use different methods depending on whether the athletes are looking to improve blood carrying capacity (LHTH, LHTL) or up-regulate muscle adaptations (LLTH). The recent innovative methods like "Repeated Sprint Training in H ypoxia (RSH)" or "Resistance Training in Hypoxia (RTH)" are likely to induce peripheral muscle adaptations and postpone fatigue [17]. These methods provide different platforms of endurancetraining which can bealtered to suit different situations in sports. It also has been used to promote injury recovery and rehabilitation among athletes [5].

A few recent studies have shown that high altitudetraining can benefit cardiorespiratory (heart and lung function) fitness and metabolic health [18] . This may favour translation of latest research findings into effective therapies and clinical practice for diseased populations (diabetes, obesity, heart disease, cancer). High altitudetraining is now used for physical activity management and injury prevention using innovative interventions. A Iso these interventions should bewell planned as prognosis related to high altitude training is based on individuals' medical condition, general physical fitness and susceptibility to high altitudesickness [13, 19].

\section{An overview of other altitude training centres in the world}

Several terrestrial altitude training sites exist around the world that offers relatively comfortable living and training conditions to athletes of all performance levels and to their coaching teams. It is crucial to identify those sites (especially the geographically closest ones to Sri Lanka) which may directly compete with the N uwara Eliya facility for offering altitudetraining opportunities to athletes. As thereareno renowned or reputed training centers in South Asia at themoment, thereasons for not having altitudetraining centres haveto beidentified. It may bebeneficial to study thereasons that led to failureof the altitude training project in Kerala, India in order to avoid similar mistakes occurring in Sri Lanka.

There are several world-renowned training centers. The most famous within the sporting community are (by ascending altitude): Premanon (1200 m in France); Thredbo (1350 m in Australia); Crans-Montana (1500 m in Switzerland); Albuquerque (1500 m in USA); Potchefstroom ( $1550 \mathrm{~m}$ in South-A frica); Snowfarm (1560 m in N ew Zealand); Pretoria (1750 m in South A frica); Boulder (1780 m in USA); Ifrane (1820 m in Morocco); St. Moritz (1820m in Switzerland); Font-Romeu (1850 m, France); Colorado Springs (1860 m, USA); Kunming (1860 m, China); Belmeken (2000m, Bulgaria); Eldoret $(2100 \mathrm{~m}$, Kenya); Flagstaff (2130m, USA); SierraN evada(2320m, Spain); Iten ( $2350 \mathrm{~m}$, Kenya); A ddis A baba ( $2400 \mathrm{~m}$, Ethiopia); Bogota (2640m, Colombia); Quito (2740m, Ecuador) and La Paz (3600 m, Bolivia).

\section{Sri Lankan context}

A systematic needs assessment through a baseline survey or through a research of a similar calibre will be mandatory to decide on the scope of the high altitude training centre for Sri Lanka. This will also allow the funds to be used cost effectively and will maximize the benefit to the athletes. The country will also gain international recognition as having an excellent AT centre catering to athletes of all kinds.

Nuwara Eliya, the siteselected to construct the High AltitudeTraining Centre (HATC) is important. The el evation of $1,868 \mathrm{~m}$ (altitude) at Numara Eliya, the sel ected area, with a mean annual temperature of $16^{\circ} \mathrm{C}\left(61^{\circ} \mathrm{F}\right)[20$ ] is ideal. Theaveragerainfall of 2000$2100 \mathrm{~mm}$ should be taken into consideration in preparing training schedules.

With therecent development in AT methods, the proposed project features the inclusion of an Environmental Chamber (where temperature, 
humidity and/ or hypoxia-hyperoxia levels are controlled) allowing near sealevel (normoxia) or more severehypoxic training sessions to be completed onsite. It should be highlighted that Kandy, the hill capital of the country, is located around 1-2 hours way from planned HATC N uwara Eiya. Training at lower elevations $(500 \mathrm{~m}$ ) can beperformed in Kandy. Use of hypoxicators at low elevations (e.g. Kandy) is an available option, where athletes can combine training at lower and higher elevations. This will provide the opportunity for advanced hypoxic training to Sri Lankan athletes and also offer unique training for international athletes.

In addition to the hypoxic stimuli, the international athletes will want to heat acclimatizeaswell, since many competitions in Asia will beheld in hot environmental conditions in the future.Theseheat/ humidity pre-acclimatization strategies will serve to prepare them very effectively for the harsh environmental conditions $\left(30-35^{\circ} \mathrm{C} / 30-40 \%\right.$ relative humidity) that they will often face when competing in South A sia [21].

The distancefrom theinternational airport and the nearest hospital and transport facilities available areimportant points to consider.

\section{Requirements and Recommendations}

Considering that the general requirements are met, the proposed Sports M edicineH uman Performanceand Research Centreat HATC should feature the following services/installations to suite the international standards:

1. Medical and sports scienceunit

2. Rehabilitation and recovery unit

3. Human performancecentre with an environmental chamber

4. Research and academic unit

5. Reception with common area and data management space

\section{G eneral requirements}

1. Thehuman and infrastructure resourcerequirements should be decided following a detailed needs assessment guided by the future plans of Ministry of Sports (MOS) Sri Lanka. The space, number of staff needed and the qualifications of the staff will depend on the findings from this needs assessment.

2. All these proposed units should be integrated with the research and academicunit with regard to data handling. Sustainable collaboration should be there with a local university of good repute through preferably a Memorandum of Understanding (MOU). Collaboration with international resource centres would be very advantageous for the future international athlete attendance.

3. Thereis a need for a satellitecentrein Colombo to test athletes at sea level.

4. It isstrongly recommended that an environmental chamber is built within the human performance centre. This would clearly maketheN uwaraEliya facility unique in the world and open doors for a range of innovative heat/ hypoxic training methods which can be offered to international athletes.

5. All facilities should be accredited according to international standards. It is essential to adhere to accepted protocols from the design stageitself.

6. There is a need to identify other high-altitude training centres in the region (especially the nearest ones) which may directly compete with theN uwara Eliya facility for altitude training. At present, there are no centres in the South Asian region. However, it is important to find the reasons for the failures (for e.g. Kerala, India), and learn from previous experiences.

7. Focus should be to have specialist service provision for a maximum of 30-40 elite/ international athletes at a time to maintain high standards. The profile of athletes who are going to use the N uwara Eliya facility will have to be clearly defined.

8. A human resource plan has to be discussed in advance. There is a need to establish clear job descriptions of different service/ careproviders (e.g. sports physicians, physiologists, clinical and research scientists, strength and conditioning coaches, sport science managers, nutritionists, physiotherapists, trainers, etc.)

\section{Summary}

Different types of AT havebeen used to enhance the endurance performance of athletes. Recent advances in AT has implemented innovativemethods to extend the benefits of physiological adaptations to improvestrength, power, promote injury recovery and rehabilitation in athl etes. In addition, it has been shown that AT is a useful therapy in injury prevention and management of certain medical conditions. 
There are no renowned HATCs in South A sia and the proposed Nuwara Eliya facility for AT is an ideal set-up as it has unique features such as high elevation, ideal temperatureand proximity for low elevation areas within a short travel time. A detailed need and feasibility assessment should be carried out when developing this project, with initiation of sustainablelocal and international collaborations and quality assurance, allowing for integration with academic and research units.

\section{References}

1. Higgins JP, TuttleT, Higgins JA. Altitudeand the heart: is going high safe for your cardiac patient? A merican $\mathrm{H}$ eart Journal 2010; 159(1): 25-32.

2. Bartsch P, Saltin B, Dvorak J. Consensus statement on playing football at different altitude. Scandinavian Journal of M edicine \& Science in Sports 2008; 18 Suppl 1: 96-9.

3. Garvican-Lewis LA, H alliday I, A bbiss CR, Saunders PU, Gore CJ. Altitude Exposure at $1800 \mathrm{~m}$ Increases Haemogl obin Mass in Distance Runners. Journal of Sports Science \& M edicine. 2015; 14(2): 413-7.

4. Girard O, Amann M, Aughey R, Billaut F, Bishop DJ, Bourdon $\mathrm{P}$, et al. Position statement - altitudetraining for improving team-sport players' performance: current knowledge and unresolved issues. British J ournal of Sports M edicine. 2013; 47 Suppl 1: i8-16.

5. Sinex JA, Chapman RF. Hypoxic training methods for improving enduranceexercise performance Journal of Sport and $\mathrm{H}$ ealth Science 2015; 4(4): 325-32.

6. Turner G, FudgeBW, PringleJSM , M axwell NS, Richardson AJ. Altitudetraining in endurance running: perceptions of elite athletes and support staff. Journal of Sports Sciences 2018: 1-10.

7. Bailey DM, DaviesB. Physiological implications of altitude training for endurance performance at sea level: a review. British Journal of Sports M edicine 1997; 31(3): 183-90.

8. Lundby C, N ielsen TK, Dela F, Damsgaard R. Theinfluence of intermittent altitude exposure to $4100 \mathrm{~m}$ on exercise capacity and blood variables. Scandinavian Journal of M edicine \& Science in Sports 2005; 15(3): 182-7.

9. Rodriguez FA, Iglesias $X$, Feriche $B$, Calderon-Soto C,
Chaverri D, Wachsmuth NB, et al. Altitude Training in Elite Swimmers for Sea Level Performance (Altitude Project). M edicine and Sscience in Sports and Exercise 2015; 47(9): 1965-78.

10. Bartsch P, Saltin B. General introduction to altitude adaptation and mountain sickness. Scandinavian J ournal of M edicine \& Science in Sports 2008; 18 Suppl 1: 1-10.

11. Park H-Y, KimS, Nam S-S. Four-week “living high training low" program enhances 3000-m and 5000-m time trials by improving energy metabolism during submaximal exercise in athletes. Journal of Exercise Nutrition \& Biochemistry 2017; 21(1): 1-6.

12. Khodaee M, Grothe HL, Seyfert JH, VanBaak K. A thletes at High Altitude. Sports Health 2016; 8(2): 126-32.

13. Luks AM, Swenson ER, Bärtsch P. Acute high-altitude sickness. European Respiratory Review 2017; 26(143).

14. KoehleMS, Cheng I, Sporer B. Canadian A cademy of Sport and Exercise Medicine position statement: athletes at high altitude. Clinical J ournal of Sport M edicine: 0 fficial Journal of the Canadian A cademy of Sport M edicine 2014; 24(2): 120-7.

15. Schommer K, Bärtsch P. Basic medical advice for travelers to high altitudes. D eutsches A rztebl att International. 2011; 108(49): 839-48.

16. Millet GP, Roels B, Schmitt $L$, Woorons $X$, Richalet JP. Combining hypoxic methods for peak performance. Sports M edicine (Auckland, NZ). 2010; 40(1): 1-25.

17. Brocherie F, Millet GP, Hauser A, Steiner T, Rysman J, WehrlinJP, etal. "LiveHigh-Train Low and High" Hypoxic Training Improves Team-Sport Performance. M edicineand Science in Sports and Exercise 2015; 47(10): 2140-9.

18. Burtscher $M$. Effects of living at higher altitudes on mortality: a narrative review. A ging and D isease 2013; 5(4): 274-80.

19. Taylor AT. High-altitudeillnesses: physiology, risk factors, prevention, and treatment. Rambam $M$ aimonides $M$ edical Journal 2011; 2(1): e0022-e.

20. Service WWI. World Meteorological Organization 2018 [cited 2018 31.10.2018]. A vailable from: http:/ / worldweather.wmo.int/ en/ home.html.

21. Racinais S, A lonso JM, Coutts AJ, Flouris AD, Girard O, González-Alonso J, etal. Consensus recommendations on training and competing in the heat. British Journal of Sports M edicine 2015; 49(18): 1164. 